\title{
Regulation of Tomato Leaf Curl Viral Gene Expression in Host Tissues
}

\author{
Ian Dry, ${ }^{1}$ Les Krake, ${ }^{1}$ Phil Mullineaux, ${ }^{2}$ and Ali Rezaian ${ }^{1}$ \\ ${ }^{1}$ CSIRO Plant Industry, Horticulture Unit, PO Box 350, Glen Osmond SA 5064, Australia; 2John Innes \\ Centre, Norwich Research Park, Colney, Norwich, NR4 7UH, UK \\ Accepted 31 January 2000.
}

The regulation of expression of the two virion-sense ( V1 and V2) and four complementary-sense $(\mathrm{C1}, \mathrm{C2}, \mathrm{C3}$, and C4) open reading frames (ORFs) of Tomato leaf curl virus (TLCV) was studied in both stably and transiently transformed Nicotiana tabacum tissues with fusions with the $\beta$ glucuronidase (GUS) reporter gene. GUS-expressing transgenic lines were obtained with each of the four complementary-sense gene-GUS fusion constructs and with truncated versions of the virion-sense gene-GUS fusion constructs (V1GUS $\Delta \mathrm{C}$ and V2GUS $\Delta \mathrm{C}$ ) lacking complementary-sense sequences encoding the $\mathrm{C} 1, \mathrm{C} 2$, and $\mathrm{C3}$ ORFs. However, little or no GUS expression was observed in kanamycin-resistant plants transformed with fulllength, virion-sense gene constructs (V1GUS and V2GUS) constituting the complete viral genome. In contrast, V1GUS and V2GUS were found to direct high-level GUS expression in transient assays with tobacco protoplasts, suggesting that integration of viral constructs containing functional, complementary-sense genes may lead to repression or deletion of the introduced constructs in transgenic tissues. V2GUS expression in the transient protoplast assay was found to be severely curtailed by specific mutation of the $\mathrm{C} 2 \mathrm{ORF}$, supporting a role for the $\mathrm{C} 2$ protein in transactivation of TLCV virion-sense gene expression. TLCV ORF-GUS constructs displayed distinctive tissue expression patterns in transgenic tobacco plants that could be divided into constitutive $(\mathrm{C} 1, \mathrm{C} 4$, and V2GUS $\Delta \mathrm{C})$, predominantly vascular $(\mathrm{C} 2, \mathrm{C3})$, or reduced expression in cells associated with the vascular bundles (V1GUS $\Delta$ C). The significance of these results is discussed in terms of current models of gene function and regulation in geminiviruses.

Additional keyword: begomovirus.

Geminiviruses are a family of plant DNA viruses characterized by their circular, single-stranded genomes encapsidated in twinned quasi-isometric particles (for review, see Hanley-Bowdoin et al. 1999). Geminivirus particles accumulate in the nuclei of infected cells where DNA replication and virus assembly take place. Their replicative forms are doublestranded, circular DNA molecules of approximately $2.7 \mathrm{~kb}$ containing up to six (viral-encoded) genes that are transcribed

Corresponding author: I. Dry; Telephone: +61883038600

Fax:+61 883038601; E-mail: ian.dry@pi.csiro.au from both strands. Geminiviruses commonly display multiple, overlapping transcripts, polycistronic RNAs, and regulation of transcription by viral-encoded proteins, making them attractive models for transcriptional regulation of plant genes.

Much of the previous work on the regulation of gene expression in geminiviruses has focused primarily on the bipartite begomoviruses Tomato golden mosaic virus (TGMV) and African cassava mosaic virus (ACMV) (Sunter and Bisaro 1991; Zhan et al. 1991; Brough et. al. 1992; Haley et al. 1992; Sunter et al. 1993; Groning et al. 1994; Sunter and Bisaro 1997) and the monopartite mastreviruses Wheat dwarf virus and Chloris striate mosaic virus (Hofer et al. 1992; Zhan et al. 1993). These studies have primarily examined the genetic location, activity, and regulation of putative promoter elements that control expression of the various viral open reading frames (ORFs) in both transient protoplast assays and stably transformed plants.

To date, little work has been carried out on the monopartite begomoviruses, such as Tomato leaf curl virus (TLCV). Although these viruses have a genome organization similar to the A component of the bipartite begomoviruses (Dry et al. 1993), they also display some unique characteristics. These include (i) the presence of a functional C4 ORF, wholly located within the $\mathrm{C} 1$ or replication-associated protein (Rep) coding region, which appears to be involved in symptom development (Krake et al. 1998; Rigden et al. 1994), and (ii) an extra virion-sense ORF (V1) that may be involved in shortdistance viral spread (Rigden et al. 1993). In this way, the genome organization of monopartite begomoviruses and the predicted functions of the proteins they encode show closer similarities to those of the monopartite Curtovirus, Beet curly top virus (BCTV). However, no information is available regarding the regulation of expression of these viral ORFs in infected host tissues.

Limited information is also available regarding the role of the $\mathrm{C} 2$ and $\mathrm{C} 3$ gene products in the infection cycle of the monopartite begomoviruses. Mutational studies with Tomato yellow leaf curl virus demonstrated an absolute requirement of C2 for infectivity in tomato (Wartig et al. 1997). We have previously shown that $\mathrm{C} 2$ and $\mathrm{C} 3$ mutants of TLCV retained the ability to replicate in tobacco leaf disks, but that C2 mutant constructs accumulated high levels of double-stranded DNA replicative forms and reduced levels of single-stranded DNA, compared with wild-type virus (Dry et al. 1997). This pattern of DNA replication was very similar to that observed with V1/V2 mutant constructs (Dry et al. 1997), suggesting a role 
for $\mathrm{C} 2$ in the transactivation of virion-sense gene expression in TLCV. A similar role for the analogous proteins (designated AL2 or AC2) has previously been demonstrated for the bipartite begomoviruses TGMV (Sunter and Bisaro 1991, 1992, 1997) and ACMV (Haley et al. 1992). In contrast, introduction of a mutation into the $\mathrm{C} 2$ gene of the monopartite BCTV had no apparent effect on infectivity, which indicated that coat protein expression was unaffected by this mutation (Stanley et al. 1992; Hormuzdi and Bisaro 1995), thereby raising questions regarding the function of $\mathrm{C} 2$ in curtoviruses.

To gain a better understanding of the regulation of gene expression in the monopartite begomovirus group, we have undertaken a study of the regulation of expression of the six ORFs of TLCV in plant cells with a $\beta$-glucuronidase (GUS) reporter gene system. The results indicate that the expression of the individual TLCV ORFs is differentially regulated by viral and host factors, leading to distinct patterns of expression in host tissues.

\section{RESULTS}

\section{Expression of TLCV gene-GUS constructs in transgenic tobacco.}

To study the activity and expression patterns of each of the TLCV genes, fusions with the GUS coding sequence were constructed as shown in Figure 1. All of the constructs, with the exception of C1GUS, were produced as in-frame, Nterminal, translational fusions with the viral ORFs, containing from 1 to 13 amino acids of the respective gene products. The C1GUS construct involved a transcriptional fusion of the GUS coding sequence within the $5^{\prime}$ untranslated region, 24 nucleotides upstream of the ATG start codon of the C1 transcript (Mullineaux et al. 1993). The virion-sense constructs were produced in two configurations: (i) V1GUS and V2GUS, constituting full-length viral genome constructs (Fig. 1B and D); and (ii) V1GUS $\Delta \mathrm{C}$ and V2GUS $\Delta \mathrm{C}$, truncated constructs with a deletion between the $B g l \mathrm{II}$ (nucleotide 663) and $\mathrm{XbaI}$ (nucleotide 1944) sites (Fig. 1C and E) to enable an examination of the potential regulatory role of the $\mathrm{C} 2$ gene product on virion-sense gene expression. TLCV-GUS constructs (Fig. $1 \mathrm{~B}-\mathrm{I})$ were cloned into the binary vector pBIN19 and transformed into Nicotiana tabacum. Control transformations were carried out with pBI121 (Jefferson et al. 1987), a pBIN19-based vector containing a cauliflower mosaic virus $35 \mathrm{~S}$ promoterGUS-NOS terminator expression cassette, to act as a positive control and with pBIN19 vector alone as a negative control.

The results shown in Table 1 demonstrate that GUSpositive $\mathrm{T}_{0}$ lines were obtained for each of the complementary-sense GUS fusion constructs, but that the frequency of kanamycin-resistant $\left(\mathrm{kan}^{\mathrm{r}}\right)$ lines showing detectable GUS expression and the mean GUS activity obtained with each construct varied markedly between each of the different viral gene-GUS fusion constructs. For example, $57 \mathrm{kan}^{\mathrm{r}}$ lines were obtained after transformation of tobacco with BINC4GUS, and of these approximately $85 \%$ showed GUS activity. In contrast, less than $9 \%$ of $\mathrm{kan}^{\mathrm{r}}$ lines recovered after transformation with BINC2GUS showed any detectable GUS activity.

In the case of transgenic lines containing the virion-sense gene-GUS fusion constructs, the highest frequency of $\mathrm{kan}^{\mathrm{r}}$ GUS-positive lines and the highest levels of GUS expression were obtained with the truncated versions of both constructs, i.e., BINV1GUS $\Delta \mathrm{C}$ and BINV2GUS $\Delta \mathrm{C}$ (Table 1). In contrast, only two GUS-positive BINV1GUS lines were obtained from the $19 \mathrm{kan}^{\mathrm{r}}$ lines recovered, and none of the $52 \mathrm{kan}^{\mathrm{r}}$ BINV2GUS lines generated were found to be GUS-positive by histochemical assay. The low frequency of GUS-positive transgenics obtained with the full-length, virion-sense constructs could not be ascribed to technical problems associated with the tobacco transformation procedure, as demonstrated by the highly efficient generation of GUS-positive transgenic lines with the pBI121 construct (Table 1).

\section{Transient expression of virion-sense gene-GUS fusion constructs in tobacco protoplasts.}

To determine whether the low efficiency of generation of GUS-positive transgenic lines with BINV1GUS and BINV2GUS was related to integration of these constructs into the tobacco genome, transient assays were carried out in tobacco protoplasts. As observed in transgenic plants (Table 1), GUS activities measured in tobacco protoplasts containing the V2GUS $\Delta$ C construct were similar to those observed with $35 \mathrm{~S}$ GUS, while activities obtained with the V1GUS $\Delta \mathrm{C}$ construct were markedly lower (Table 2). However, in contrast to the results obtained with stably transformed tobacco lines, the full-length, virion-sense gene constructs, V1GUS and V2GUS, showed extremely high levels of GUS expression, exceeding 200 times that obtained with the control 35S-GUS construct. Co-electroporation of V2GUS and V2GUS $\Delta$ C, with a dimeric clone of wild-type TLCV (TLCV2.0), resulted in a marked increase in GUS expression from V2GUS $\Delta \mathrm{C}$, but not from V2GUS (Table 2). This suggested that gene products produced by the wild-type virus, but not by the truncated V2GUS $\Delta C$ construct, were activating virion-sense gene expression in tobacco protoplasts.

To test this hypothesis further, two mutant constructs were produced. In the first construct, V2GUSC1mut, the ATG initiation codon of the $\mathrm{C} 1 \mathrm{ORF}$ was mutated to a TAG stop codon to inhibit $\mathrm{C} 1(\mathrm{Rep})$ production. GUS expression was found to be reduced by an average of $92 \%$ in protoplasts transfected with V2GUSC1mut, compared with the V2GUS construct (Table 2). This indicated that Rep-mediated replication of the introduced, plasmid-based TLCV-GUS construct was a major contributing factor to the high level of GUS expression observed with the V2GUS construct in tobacco protoplasts.

In the second mutant construct, V2GUSC2mut, a premature stop codon was introduced into the $\mathrm{C} 2 \mathrm{ORF}$ at nucleotide position 1525, immediately downstream of the termination codon of the $\mathrm{C} 1 \mathrm{ORF}$. This mutation was designed to prevent production of a functional $\mathrm{C} 2$ protein but have no effect on the production of Rep protein. Table 2 shows that GUS expression from the V2GUS construct, in tobacco protoplasts, was significantly reduced by specific mutation of the $\mathrm{C} 2 \mathrm{ORF}$, which is consistent with transactivation of TLCV virion-sense gene expression by the $\mathrm{C} 2$ gene product.

\section{TLCV genes show distinct tissue expression patterns in transgenic tobacco.}

The highest expressing lines of each TLCV gene-GUS fusion construct, as shown in Table 1, were selfed and progeny seed germinated on kanamycin. $\mathrm{T}_{1}$ siblings from five independent $\mathrm{T}_{0}$ lines for each construct (except for BINC2GUS, for which only two GUS-positive lines were available), were 
selected at random and analyzed histochemically for GUS expression in leaf, stem, and root tissues to enable accurate description of expression patterns associated with each TLCV gene-GUS fusion construct, as summarized in Table 3. GUS expression in the $T_{1}$ progeny of the BINV1GUS lines was found to be too low to enable tissue expression patterns to be accurately determined by this method, and these progeny were therefore excluded from the analysis. In certain tobacco tissues, expression patterns were not consistent in all $\mathrm{T}_{0}$ lines and these are indicated by ( \pm ) in Table 3 .

Tissue expression patterns displayed by transgenic tobacco plants containing TLCV-GUS fusion constructs could be di-
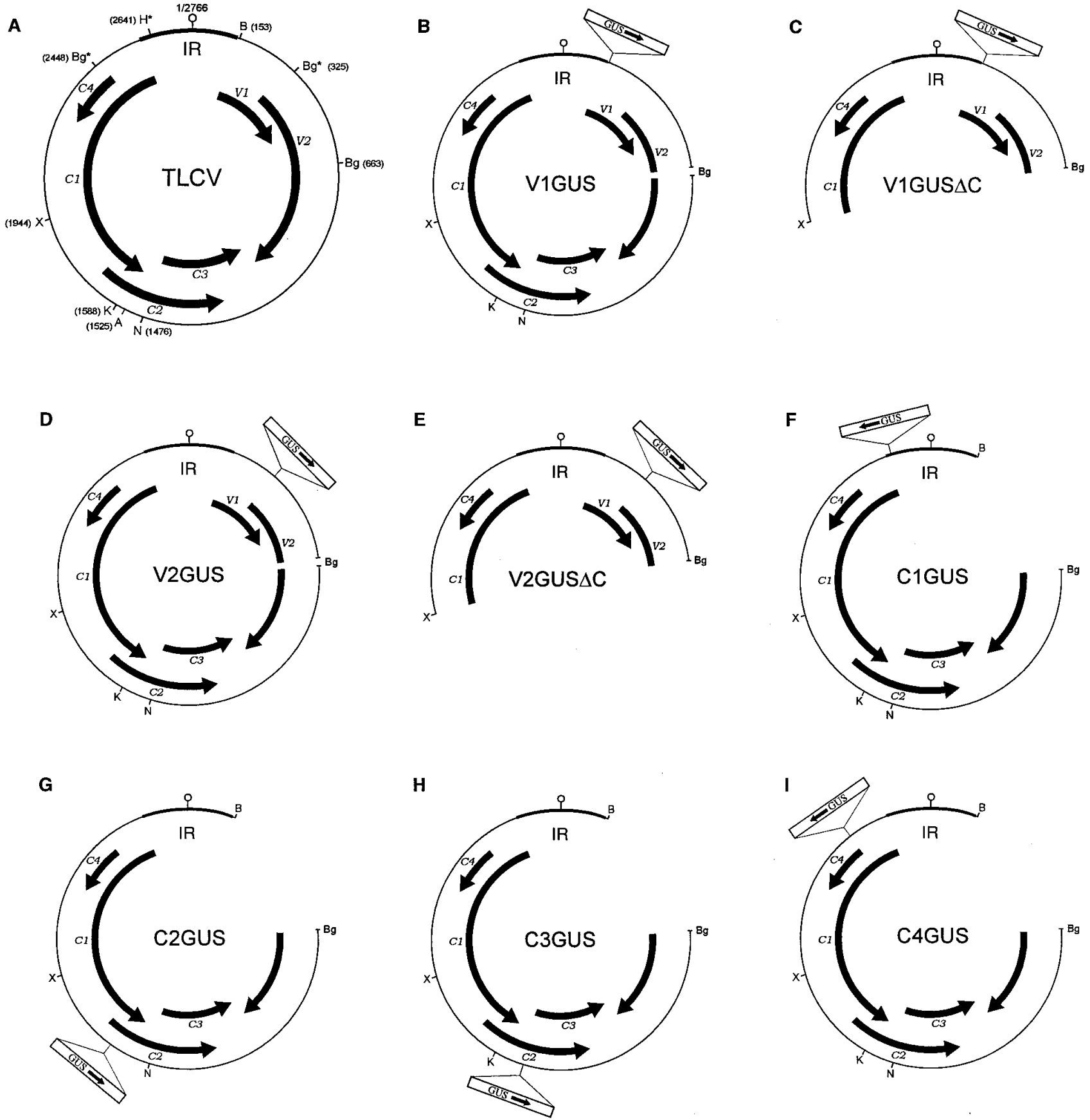

Fig. 1. Schematic representation of Tomato leaf curl virus (TLCV) promoter- $\beta$-glucuronidase (GUS) fusion constructs. A, Genome organization of TLCV. Circular, double-stranded, replicative form of the viral genome is represented by the thin black line. The intergenic region (IR) containing the origin of replication, including the conserved geminiviral stem-loop motif (top of each circle), is shown as a thick black line. Locations of the two virion-sense (V1, V2) and four complementary-sense $(\mathrm{C} 1, \mathrm{C} 2, \mathrm{C} 3, \mathrm{C} 4)$ viral open reading frames (ORFs) are shown by arrows. Position of restriction sites used for construction of TLCV-GUS fusions are indicated: B, BamHI; Bg, BglII; N, NcoI; A, AsnI; K, KpnI; X, XbaI; H, HindIII. * = restriction sites introduced by site-directed mutagenesis. B-I, Promoter-GUS fusion constructs cloned into pBIN19 for tobacco transformation. Open box (GUS $\rightarrow$ ) represents a $2.1-\mathrm{kb}$ fragment containing a GUS-NOS terminator cassette as described in Materials and Methods. 
Table 1. Summary of $\beta$-glucuronidase (GUS) expression from Tomato leaf curl virus (TLCV)-GUS fusion constructs in transgenic tobacco ${ }^{\mathrm{a}}$

\begin{tabular}{|c|c|c|c|}
\hline \multirow[b]{2}{*}{ Construct } & \multirow{2}{*}{$\begin{array}{l}\text { No. GUS-positive } \\
\text { lines / total no. kan } \\
\text { transgenic lines }\end{array}$} & \multicolumn{2}{|c|}{ GUS activity } \\
\hline & & $\begin{array}{c}\text { Mean } \\
\left(\text { pmol MU } \text { min }^{-1}\right.\end{array}$ & $\begin{array}{c}\text { Range } \\
\text { mg prot }^{-1} \text { ) }\end{array}$ \\
\hline BINC1GUS & $15 / 26$ & $420(7)$ & $63-1629$ \\
\hline BINC2GUS & $2 / 23$ & $357(2)$ & $319-396$ \\
\hline BINC3GUS & $5 / 14$ & $154(5)$ & $123-243$ \\
\hline BINC4GUS & $48 / 57$ & $2419(10)$ & $578-4450$ \\
\hline BINV1GUS & $2 / 19$ & $76(2)$ & 54-99 \\
\hline BINV1GUS $\Delta C$ & $18 / 29$ & $263(6)$ & 84-462 \\
\hline BINV2GUS & $0 / 52$ & - & - \\
\hline BINV2GUS $\Delta \mathrm{C}$ & $28 / 56$ & $2722(6)$ & $1416-6464$ \\
\hline pBI121 & $8 / 8$ & $6042(5)$ & $1204-11200$ \\
\hline pBIN19 & - & $<1$ & - \\
\hline
\end{tabular}

${ }^{a}$ All kanamycin resistant $\left(\operatorname{kan}^{\mathrm{r}}\right)$ in vitro cultured $\mathrm{T}_{0}$ lines were initially screened for positive GUS expression by histochemical or fluorometric assay as described in Materials and Methods. Highest expressing lines ( 2 to 10 per construct) were then re-assayed for GUS activity. Numbers in parentheses indicate number of independent $\mathrm{T}_{0}$ lines assayed for each construct. Results are sum of two separate extractions involving duplicate assays. Activity measurements are compared with that obtained with tobacco plants transformed with pBIN19 vector alone.

Table 2. Transient expression of virion-sense Tomato leaf curl virus (TLCV) promoter- $\beta$-glucuronidase (GUS) fusion constructs in tobacco protoplasts $^{\mathrm{a}}$

\begin{tabular}{lcccc}
\hline & \multicolumn{4}{c}{ Relative GUS activity (\%) } \\
\cline { 2 - 5 } Construct & Exp 1 & Exp 2 & Exp 3 & Exp 4 \\
\hline Control (no DNA) & 0.01 & 0.06 & 0.11 & 0.01 \\
35S-GUS & 0.49 & 0.42 & $-\mathrm{b}$ & - \\
V1GUS & 74.7 & 106 & - & - \\
V1GUS $\Delta C$ & 0.15 & 0.08 & - & - \\
V2GUS & 100 & 100 & 100 & 100 \\
V2GUS $\Delta C$ & 0.60 & 0.39 & - & - \\
V2GUS + TLCV2.0 & - & 84 & - & - \\
V2GUS $\Delta$ C + TLCV2.0 & - & 15.8 & - & - \\
V2GUSC1mut & - & - & 7.4 & 10.5 \\
V2GUSC2mut & - & - & 15.5 & 12.5 \\
\hline
\end{tabular}

${ }^{\text {a }}$ Protoplasts were electroporated with $20 \mu \mathrm{g}$ of plasmid DNA and assayed for GUS activity as described in Materials and Methods. All electroporations were carried out with viral promoter-GUS fusion constructs cloned into $\mathrm{BS}_{-} \mathrm{SK}^{+}$plasmid vector. A pUC-based plasmid containing a 35S-GUS expression cassette was included in some experiments for comparison. Activities were adjusted for protein concentration of individual protoplast samples and are expressed as a percentage of the rate obtained with the V2GUS construct in each experiment. Absolute V2GUS activities ranged from 222 to 2,200 pmol MU min $^{-1} \mathrm{mg}$ protein ${ }^{-1}$.

$\mathrm{b}_{-}=$construct not tested in this experiment. vided into three distinct types (Table 3). The most common type was that displayed by transgenic lines containing either the BINC1GUS, BINC4GUS, or BINV2GUS $\Delta \mathrm{C}$ construct, in which all tissues examined showed GUS expression except for the root cortex. Strong GUS staining was seen in both the vascular bundle and mesophyll tissues of leaves (Fig. 2A and B) and all tissues of the stem (Fig. 2C) in BINV2GUS $\Delta C$ and BINC4GUS transgenic lines. In roots, GUS expression was found to be associated predominantly with the root tip and to a lesser extent the vascular bundle, with no apparent staining of the cortex (Fig. 2D).

A second, unique type of expression pattern was displayed by plants containing the BINV1GUS $\Delta \mathrm{C}$ construct (Table 3 ). These plants showed good GUS expression within the mesophyll cells of leaves, but significantly reduced expression in cells associated with the vascular bundles and supporting collenchyma tissue surrounding the vascular bundles in leaf, stem, and root tissue, compared with the BINV2GUS $\Delta \mathrm{C}$ and BINC4GUS transgenics (Fig. 2E-H).

A third type of tissue expression pattern was observed in tissues of tobacco plants transformed with the BINC2GUS and BINC3GUS constructs (Table 3) that contrasted sharply with the patterns observed with the other TLCV genes. The expression pattern obtained with both constructs was nearly identical, with GUS activity associated predominantly with the vascular tissues in leaves, stems, and roots, with little or no expression in other tissues (Fig. 2I-L).

\section{DISCUSSION}

The work described here represents the first comprehensive study of both the activity and the tissue expression patterns of all the major genes of a single geminivirus. Furthermore, as this study has been carried out with a monopartite Begomovirus (TLCV), information has been obtained regarding the expression of the important functional genes, V1 and $\mathrm{C} 4$, for which no expression analysis has previously been undertaken in any other geminivirus.

Stable integration of certain TLCV gene-GUS fusion constructs into tobacco cells resulted in GUS activities that were markedly different from those observed in the transient assays. The activity of the full-length, virion-sense gene-GUS constructs was found to be either markedly reduced (i.e., BINV1GUS) or totally absent (i.e., BINV2GUS) in transgenic tobacco plants, in comparison to plants transformed with truncated versions of these constructs, i.e., BINV1GUS $\Delta \mathrm{C}$ and BINV2GUS $\Delta \mathrm{C}$ (Table 1). In contrast, both the full-length and truncated versions of the V1 and V2-GUS fusion constructs

Table 3. Tomato leaf curl virus (TLCV) promoters show differential expression patterns in transgenic tobacco tissues ${ }^{\mathrm{a}}$

\begin{tabular}{|c|c|c|c|c|c|c|c|c|}
\hline \multirow[b]{2}{*}{ Construct } & \multicolumn{2}{|c|}{ Leaf } & \multicolumn{3}{|c|}{ Stem } & \multicolumn{3}{|c|}{ Root } \\
\hline & Vascular bundle & Mesophyll & Pith & Vascular bundle & Cortex & Cortex & Vascular bundle & Tip \\
\hline BINC1GUS & + & + & \pm & + & + & _- & + & + \\
\hline BINC4GUS & + & + & \pm & + & + & - & \pm & + \\
\hline BINV2GUS $\Delta \mathrm{C}$ & + & + & \pm & + & + & - & \pm & + \\
\hline BINV1GUS $\Delta \mathrm{C}$ & \pm & + & _- & \pm & _- & _- & _- & + \\
\hline BINC2GUS & + & _ & _ & + & _- & _- & + & + \\
\hline BINC3GUS & + & - & - & + & - & - & \pm & + \\
\hline
\end{tabular}

${ }^{a}$ Summary of the $\beta$-glucuronidase (GUS) expression patterns observed in $\mathrm{T}_{1}$ siblings of the highest expressing $\mathrm{T}_{0}$ lines obtained with each TLCV-GUS fusion construct. Siblings from five independent To lines were analyzed for each promoter-GUS construct, except for BINC2GUS, for which only two GUS-positive lines were available (see Table 1 ). \pm = weak or variable expression for this tissue across the five $\mathrm{T}_{0}$ lines examined. 
were functional as episomal expression vectors in tobacco protoplasts (Table 2). Repression of geminiviral, virion-sense promoter activity upon integration of full-length, viral constructs into transgenic plants has previously been reported by Sunter and Bisaro (1997). Working with the coat protein gene promoter of TGMV, they observed that Nicotiana benthamiana plants transformed with a full-length TGMV genomic construct in which the coat protein gene had been replaced with the GUS gene showed no GUS expression, whereas plants transformed with a truncated version of this construct that lacked most of the complementary-sense gene sequences (as used in this study) resulted in strong GUS expression in the vascular tissues but not in the mesophyll tissues. Based on these observations, Sunter and Bisaro (1997) postulated the existence of a cis-acting repressor element located within, or near to, the AL2 (C2) ORF of TGMV that represses coat protein gene promoter expression in the absence of the transcriptional activator protein, AL2 (C2).

Whether such regulatory processes also control the expression of both the V1 and V2 genes of TLCV remains to be determined. However, there is evidence to suggest that, in our experiments, the lack of virion-sense gene expression observed in transgenic plants transformed with complementarysense viral sequences may also be associated with a positive selection against integration of the TLCV C1 (Rep) gene into transgenic cells. This evidence comes from an examination of the integrated structure of the BINV1GUS, BINC2GUS, and BINC3GUS constructs within the limited number of GUS- positive, transgenic lines obtained following tobacco transformation (Table 1). Using polymerase chain reaction analysis with a range of TLCV- and GUS-specific primers, we have found evidence to indicate that each of these $\mathrm{kan}^{\mathrm{r}}$, GUSpositive, transgenic lines contains significant deletions of the introduced viral gene-GUS construct within the complementary-sense region spanning the $\mathrm{C} 1 \mathrm{ORF}$, such that each of these GUS-positive lines is, in effect, lacking a functional C1 gene (I. B. Dry and M. A. Rezaian, unpublished). Thus, there appears to have been a positive selection for transgenic cells in which there has been incomplete insertion of the pBIN19 TDNA segment, resulting in transfer of the selectable marker $\left(\operatorname{kan}^{r}\right)$ but not the entire gene construct of interest. This is commonly observed in transformation experiments with pBIN19-based constructs (Van Engelen et al. 1995).

When these observations are considered together with the results shown in Table 1, it can be seen that the only stable, GUS-positive, transgenic lines that were recovered from these transformation experiments were those involving TLCV-GUS constructs in which the $\mathrm{C} 1$ gene had been inactivated or deleted either prior to introduction into the tobacco cells (Fig. 1) or during the transformation process. Such results strongly suggest that the integrated expression of the TLCV Rep gene may be lethal in tobacco cells, possibly mediated through interaction with plant cell cycle regulatory elements leading to a disruption of cell division (Hanley-Bowdoin et al. 1999). Further support for this hypothesis comes from the results of transformation experiments designed to generate transgenic

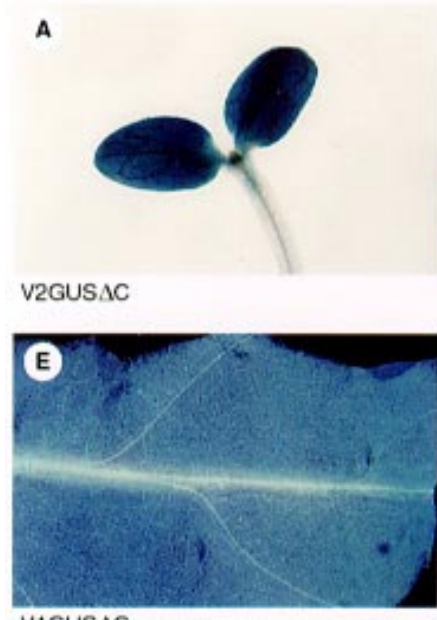

VIGUSAC

I

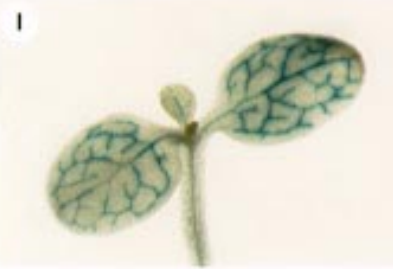

C2Gus

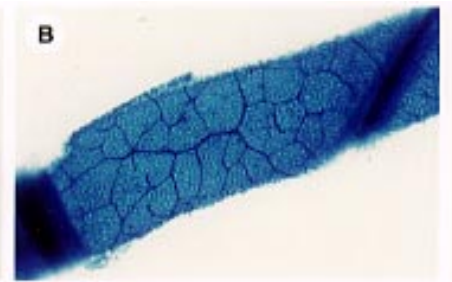

V2GUSAC

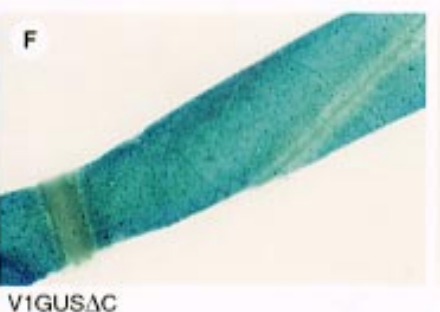

J

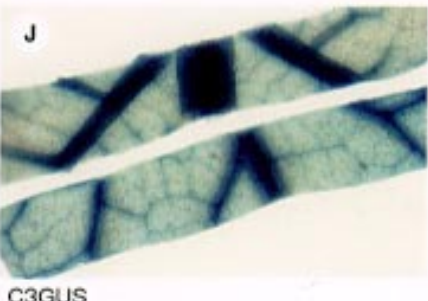

c

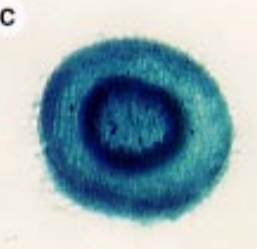

C4GUS

G

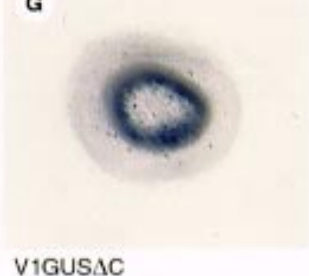

K

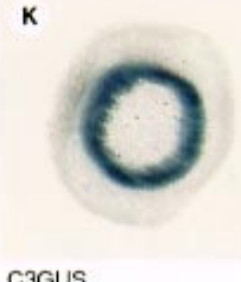

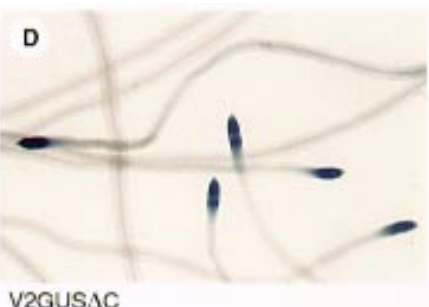

V2GUSAC

H

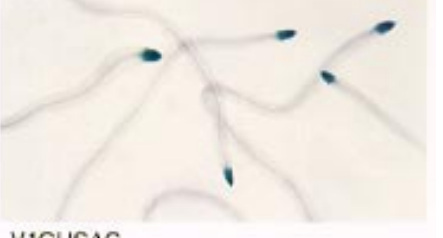

VIGUSAC

L

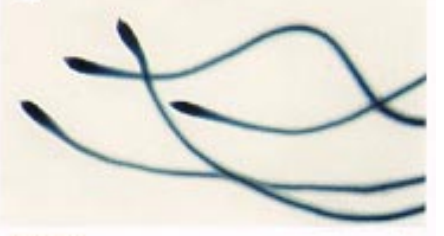

C2Gus

Fig. 2. Expression patterns of Tomato leaf curl virus (TLCV) promoter- $\beta$-glucuronidase (GUS) constructs in transgenic tobacco tissues. GUS expression was localized histochemically as described in Materials and Methods. A-D, E-H, and I-L each illustrate examples of different GUS expression patterns observed, as described in the text. A, BINV2GUS $\Delta$ C, seedling showing cotyledons and stem $(\times 20)$. B, BINV2GUS $\Delta$ C, leaf slice $(\times 32)$. C, BINC4GUS, transverse stem section $(\times 20)$. D, BINV2GUS $\Delta$ C, roots $(\times 20)$. E, BINV1GUS $\Delta$ C, leaf slice $(\times 32)$. F, V1GUS $\Delta$ C, leaf slice $(\times 32)$. G, BINV1GUS $\Delta$ C, transverse stem section $(\times 20)$. H, BINV1GUS $\Delta$ C, roots $(\times 20)$. I, BINC2GUS, seedling showing cotyledons and stem $(\times 20)$. J, BINC3GUS, leaf slices showing lower (top) and upper (bottom) surfaces $(\times 32)$. K, BINC3GUS, transverse stem section $(\times 20)$. L, BINC2GUS, roots $(\times 20)$. 
plants constitutively expressing the Rep gene of a monopartite begomovirus. Attempts to express the C1 ORF of TLCV (this laboratory, data not shown) or the closely related monopartite Begomovirus, TYLCV (Bendahmane and Gronenborn 1997) in transgenic tobacco have been totally unsuccessful. In contrast, the $\mathrm{C} 1$ homolog (AL1) of the bipartite Begomovirus TGMV has been successfully introduced and expressed in transgenic tobacco and shown to functionally complement TGMV replication mutants (Hanley-Bowdoin et al. 1990). The markedly different response of tobacco cells to Rep protein from the monopartite and bipartite begomoviruses raises interesting questions regarding the relative functional role(s), in viral infection, of Rep proteins from these two geminiviral subgroups.

Virion-sense gene expression in tobacco protoplasts was found to be severely curtailed by mutation of the C2 ORF (V2GUSC2mut; Table 2). This is in agreement with the conclusions obtained from leaf-strip assays involving a TLCV C2 mutant (Dry et al. 1997) and is consistent with the involvement of the $\mathrm{C} 2$ protein in transactivation of TLCV virionsense gene expression. Comparison of GUS expression activities obtained with either the nonreplicating (V2GUS $\Delta \mathrm{C}$ versus V2GUSC1mut) or replicating (V2GUS versus V2GUSC2mut) constructs suggests that transactivation of the V2 promoter by C2 may be of the order of six- to 20 -fold in tobacco protoplasts (Table 2). While this is lower than the 60fold increase observed for transactivation of the TGMV coat protein promoter by the AL2 (C2) protein (Sunter and Bisaro 1991), it does indicate that the C2 protein of TLCV has greater functional similarity to the $\mathrm{C} 2$ proteins of the bipartite begomoviruses, TGMV (Sunter and Bisaro 1991) and ACMV (Haley et al. 1992) than to the monopartite Curtovirus, BCTV, for which no transactivating function has been demonstrated (Stanley et al. 1992; Hormuzdi and Bisaro 1995).

In transgenic plants containing the truncated versions of the virion-sense constructs (BINV1GUS $\Delta \mathrm{C}$ and BINV2GUS $\Delta \mathrm{C}$ ), gene expression does not appear to be dependent on $\mathrm{C} 2$ transactivation (Table 2) and is activated by host transcription factors within most cell types examined (Table 3; Fig. 2). This suggests that other regulatory sequences present within the complete TLCV genome, like the putative repressor element in TGMV (Sunter and Bisaro 1997), may operate to restrict virion-sense gene expression in the absence of $\mathrm{C} 2$ protein. It is also interesting to note that a truncated TGMV coat protein gene promoter was found to be activated by host transcription factors within the vascular tissues of transgenic tobacco, but that expression in mesophyll cells was still strictly dependent on the presence of the viral transcriptional activator protein, AL2 (C2) (Sunter and Bisaro 1997). This may reflect differences in the tissue-specific production of transcription factors within the mesophyll cells of the different tobacco genotypes used for each study, i.e., N. tabacum (this study) versus $N$. benthamiana (Sunter and Bisaro 1997). Alternatively, these results may indicate the existence of fundamental differences in the interaction of host factors with the virion-sense promoters of the bipartite and monopartite begomoviruses. Whether these apparent differences are conserved between other monopartite and bipartite begomoviruses remains to be tested.

It is clear from the results in Table 2 that Rep-mediated amplification of the introduced plasmid construct was contributing to the high levels of GUS activity measured in protoplasts electroporated with V1GUS or V2GUS. Brough et al. (1992) observed similarly high levels of viral promoter-driven GUS expression (i.e., 100 times greater than 35S) in protoplasts transfected with plasmid vectors containing one and a half copies of TGMV DNA A in which the coat protein gene had been replaced by GUS. In that study, TGMV A DNA monomers were released from tandemly repeated copies within the introduced plasmid vector, and replicated as a circular, unitlength genome containing the GUS gene. As all of the TLCVGUS constructs used in our experiments were monomers or deleted monomers, release and subsequent amplification of the viral-GUS monomer within these transfected protoplasts would have been unlikely, and the high GUS expression would appear to have resulted from amplification of the entire 7.7-kb TLCV-GUS plasmid. Experiments with Wheat dwarf virus have previously shown that geminiviral replication in suspension cells or protoplasts was unaffected by the insertion of an additional $3 \mathrm{~kb}$ of foreign DNA (Laufs et al. 1990; Matzeit et al. 1991). This demonstrates that geminiviral replication in individual host cells is not strictly size limited, unlike the processes of encapsidation and systemic spread through host tissues (Timmermans et al. 1994).

Histochemical analysis of GUS expression patterns in transgenic tobacco tissues demonstrated marked differences between the expression of different TLCV ORFs in different cell types. A number of TLCV-GUS fusion constructs, including $\mathrm{C} 1, \mathrm{C} 4$, and $\mathrm{V} 2(\Delta \mathrm{C})$, displayed essentially constitutive expression patterns in aerial tissues (Fig. 2), similar to that observed with reporter genes driven by promoters from other plant DNA viruses, such as the $35 \mathrm{~S}$ promoter from Cauliflower mosaic virus. In contrast, the pattern of expression of the V1 $(\Delta C)$ ORF showed some significant differences from that of the $\mathrm{V} 2(\Delta \mathrm{C})$, in terms of reduced expression in tissues associated with and surrounding the vascular bundles (Fig. 2). As it was only possible to obtain tissue expression data for the virion-sense genes with the truncated viral constructs, the significance of this differential expression, in terms of the regulation of virion-sense gene expression in infected tissues, is uncertain. However, these data do provide convincing evidence that these two, overlapping, virion-sense ORFs are translated from different transcripts, as predicted from our previous mapping studies (Mullineaux et al. 1993). How the differential regulation of expression of these two virion-sense ORFs is mediated from a common virion-sense promoter region remains to be determined.

The high degree of similarity observed between the GUS expression patterns in transgenic tobacco plants containing the C2GUS and C3GUS constructs (Table 3; Fig. 2) supports the hypothesis that both the $\mathrm{C} 2$ and $\mathrm{C} 3$ proteins are translated from a single bicistronic transcript (Mullineaux et al. 1993). It is interesting to speculate as to the functional significance of the strong vascular-bundle localized expression pattern associated with C2 and C3 expression. As TLCV is a whiteflytransmitted geminivirus, high-level replication and encapsidation of TLCV within the phloem-associated cells would ensure efficient insect transmission. We have demonstrated both in this study (Table 2), and previously (Dry et al. 1997), that coat protein (V2) production by full-length, replicating TLCV is dependent on $\mathrm{C} 2$ expression. Furthermore, it has been established from work with other begomoviruses that the $\mathrm{C} 3$ protein has an important role as a replication enhancer 
(Hanley-Bowdoin et al. 1999). Based on the strong vascularbundle associated expression patterns displayed by the C2GUS and C3GUS constructs in transgenic tobacco, we suggest that both viral replication and coat protein expression may be specifically activated by $\mathrm{C} 2$ and $\mathrm{C} 3$ expression in vascular tissues, thereby ensuring the availability of high levels of encapsidated virus for insect transmission.

\section{MATERIALS AND METHODS}

The nucleotide numbering of the restriction sites described in the clones listed below refers to the published sequence of TLCV (Dry et al. 1993). TLCV2.0 is a dimeric clone of the full-length, infectious XbaI TLCV clone described in Dry et al. (1993) cloned into pGem-3Z (Promega, Madison, WI). The plasmid pBI121 was obtained from Clontech (Palo Alto, CA). All gene fusions and site-directed mutations were confirmed by sequencing.

\section{Cloning of TLCV gene-GUS reporter fusion constructs.}

The locations of the six viral ORFs on the doublestranded replicative form of TLCV are shown in Figure 1A. Each of the ORFs was fused to the Escherichia coli uidA gene coding for GUS at the positions indicated (Fig. 1B-I). The cloning strategy used for each viral gene-GUS fusion construct was based on the introduction of a $2.1-\mathrm{kb} \mathrm{BamHI}$ fragment containing a GUS-NOS-terminator cassette obtained from one of the pBI201.1, pBI201.2, or pBI201.3 vector series (Clontech), which have the start codon of the GUS ORF shifted by 1 nucleotide relative to the BamHI site in the polylinker region to enable in-frame fusions with the viral ORFs. Each of the original vectors in the pBI201 series was initially modified by insertion of a BamHI linker into an EcoRI site located $3^{\prime}$ of the NOS terminator (NOSter) sequence to allow removal of this BamHI GUS fragment. Unless otherwise stated, all site-directed mutagenesis was carried out in pAlter (Promega). For production of V1GUS, C2GUS, and C3GUS, a full-length $B g l I I$ monomer of TLCV was first cloned into the BamHI site of pBluescript (BS)$\mathrm{SK}^{+}$(Stratagene, San Diego, CA). For the production of V2GUS and C4GUS, a full-length $B g l$ II monomer of TLCV was first cloned into the BamHI site of pAlter.

\section{V1GUS/V1GUS $\Delta$ C.}

A BamHI GUS-NOSter fragment was cloned into the BamHI site (nucleotide 153) of TLCV in-frame with the first 2 amino acids of the V1 ORF to give V1GUS. The full-length TLCV genome, with introduced GUS-NOSter cassette, was ligated as a HindIII/SpeI fragment into pBIN19 to give BINV1GUS (Fig. 1B). A modified version of V1GUS was produced by deletion of the TLCV genomic sequence from $B g l I I$ (nucleotide 663) to $X b a I$ (nucleotide 1944) to give V1GUS $\Delta$ C. A HindIII/XbaI fragment from V1GUS $\Delta \mathrm{C}$ was cloned into pBIN19 to give BINV1GUS $\Delta \mathrm{C}$ (Fig. 1C).

\section{V2GUS/V2GUS $\Delta$ C.}

A $B g l$ II site was introduced into the V2 ORF at nucleotide position 325 by site-directed mutagenesis and the TLCV monomer was then cloned into $\mathrm{BS}_{-} \mathrm{SK}^{+}$as a HindIII/SmaI fragment. A BamHI GUS-NOSter fragment was cloned into the introduced $B g l I I$ site, in-frame with the first 7 amino acids of the V2 ORF, to give V2GUS. The full-length TLCV genome, with introduced GUS-NOSter cassette, was released as a HindIII/SpeI fragment and ligated into pBIN19 to give BINV2GUS (Fig. 1D). A modified version of V2GUS was produced by deletion of the TLCV genomic sequence from $B g l I I$ (nucleotide 663) to $\mathrm{XbaI}$ (nucleotide 1944) to give V2GUS $\Delta$ C. A HindIII/XbaI fragment from V2GUS $\Delta$ C was cloned into HindIII/XbaI cut pBIN19 to produce BINV2GUS $\Delta \mathrm{C}$ (Fig. 1E).

\section{C1GUS.}

A HindIII site was introduced at nucleotide position 2641, within the $5^{\prime}$ untranslated region of the $\mathrm{C} 1$ transcript (Mullineaux et al. 1993), by site-directed mutagenesis of a SacI (nucleotide 2330)-BamHI (nucleotide 153) fragment of TLCV. This fragment was then recloned back into a full-length $B g l I I-$ digested TLCV monomer in the BamHI site of $\mathrm{BS}_{-} \mathrm{SK}^{+}$. The introduced HindIII site at nucleotide 2641 was digested, endfilled with T4 DNA polymerase, and a $B g l$ II linker introduced. A BamHI GUS-NOSter fragment was cloned into the introduced $B g l I I$ site, producing a transcriptional fusion with the $\mathrm{C} 1 \mathrm{ORF}$, to give C1GUS. A BamHI/SpeI fragment encompassing the TLCV genome from $B g l$ II (nucleotide 663) to BamHI (nucleotide 153), and containing the introduced GUSNOSter cassette at nucleotide 2641, was ligated into pBIN19 to produce BINC1GUS (Fig. 1F).

\section{C2GUS.}

A $B g l$ II linker was introduced into the $K p n I$ site at nucleotide position 1588. A BamHI GUS-NOSter fragment was cloned into the introduced $B g l I I$ site, in-frame with the first 13 amino acids of the C2 ORF, to give C2GUS. A BamHI/SpeI fragment encompassing the TLCV genome from BglII (nucleotide 663) to BamHI (nucleotide 153), and containing the introduced GUS-NOSter cassette at nucleotide 1588, was ligated into pBIN19 to produce BINC2GUS (Fig. 1G).

\section{C3GUS.}

A $B g l$ II linker was introduced into the NcoI site at nucleotide 1476. A BamHI GUS-NOSter fragment was cloned into the introduced $B g l I I$ site, in-frame with the start codon of the C3 ORF, to give C3GUS. A BamHI/SpeI fragment encompassing the TLCV genome from $B g l$ II (nucleotide 663) to BamHI (nucleotide 153), and containing the introduced GUSNOSter cassette at nucleotide 1476, was transferred into pBIN19 to produce BINC3GUS (Fig. 1H).

\section{C4GGUS.}

A $B g l$ II site was introduced into the C4ORF at nucleotide position 2448 by site-directed mutagenesis and the TLCV monomer then cloned into $\mathrm{BS} \mathrm{SK}^{+}$as a HindIII/SmaI fragment. A BamHI GUS-NOSter fragment was cloned into the introduced $B g l I I$ site in-frame with the $\mathrm{C} 4 \mathrm{ORF}$ to give C4GUS. A fragment encompassing the TLCV genome from BglII (nucleotide 663) to BamHI (nucleotide 153), and containing the introduced GUS-NOSter cassette at nucleotide position 2448, was ligated into pBIN19 to give BINC4GUS (Fig. 1I).

Two additional mutant constructs, V2GUSC1mut and V2GUSC2mut, were produced in $\mathrm{BS}^{-\mathrm{SK}^{+}}$for protoplast expression studies. V2GUSC1mut was produced by replacement 
of the 2256 nucleotide section from $B g l$ II (nucleotide 663) to BamHI (nucleotide 153) in V2GUS (Fig. 1) by the equivalent genome fragment from a C1-mutant TLCV construct described in Rigden et al. (1996), in which the ATG initiation codon of the $\mathrm{C} 1 \mathrm{ORF}$ at nucleotide 2615 was mutated to a TAG termination codon. V2GUSC2mut was produced by the addition of two additional nucleotides (AA) into V2GUS at nucleotide position 1525 by site-directed mutagenesis, causing the formation of a premature in-frame TAA stop codon in the C2 ORF.

\section{Protoplast transfection.}

Protoplasts were prepared from Nicotiana tabacum (NT-1) suspension cells essentially as described by Aryan et al. (1991). Plasmid DNA was prepared with a Qiagen Plasmid Midi Kit (Qiagen, Victoria, Australia) according to the manufacturer's instructions. Protoplasts were resuspended to approximately $2.5 \times 10^{6}$ cells $\mathrm{ml}^{-1}$ in electroporation buffer $\left(150 \mathrm{mM} \mathrm{NaCl}, 5 \mathrm{mM} \mathrm{CaCl}{ }_{2}, 0.2 \mathrm{M}\right.$ mannitol, and $10 \mathrm{mM}$ HEPES [ $N$-2-hydroxyethylpiperazine- $N$-2-ethanesulfonic acid], $\mathrm{pH}$ 7.2), electroporated with $20 \mu \mathrm{g}$ of plasmid DNA with a Gene Pulser apparatus (Bio-Rad, Richmond, CA) set at $625 \mathrm{~V} \mathrm{~cm}^{-1}$ and $500 \mu \mathrm{F}$ capacitance, and cultured in the dark at 25 to $27^{\circ} \mathrm{C}$. Transfected protoplasts were collected after 48 h by centrifugation at $40 \times g$ for $5 \mathrm{~min}$ and assayed for GUS activity.

\section{Plant transformation.}

Tobacco (N. tabacum cv. Samsun) was transformed with viral gene-GUS fusion constructs essentially by the method of Horsch et al. (1985). Binary constructs were introduced into Agrobacterium tumefaciens LBA4404 by electroporation with a Gene Pulser apparatus (Bio-Rad) according to the manufacturer's specifications. Transgenic shoots were selected on kanamycin at a concentration of $250 \mu \mathrm{g} \mathrm{ml}^{-1}$ and grown at 25 to $27^{\circ} \mathrm{C}$ under artificial light $\left(150 \mu \mathrm{mol} \mathrm{s} \mathrm{s}^{-1}\right)$ for $16 \mathrm{~h}$ per day.

\section{Analysis of GUS activity.}

Quantitative measurements of GUS activity in extracts of protoplasts and transgenic leaf material were carried out by a fluorometric assay (Jefferson 1987). Protein concentration was measured with Bio-Rad protein assay reagent according to the manufacturer's instructions.

Histochemical detection of GUS activity in tissues of transgenic plants was carried out essentially as described by Jefferson (1987). For analysis of tissue expression patterns in $T_{1}$ generation progeny, selected $\mathrm{T}_{0}$ lines were allowed to selffertilize and the resulting seeds germinated on MS (Murashige-Skoog) media containing kanamycin (100 $\mu \mathrm{g}$ $\mathrm{ml}^{-1}$ ). Five siblings of each selected transgenic line were analyzed for GUS expression patterns. Tissues were first cut into 1- to 2-mm sections in $100 \mathrm{mM}$ phosphate buffer ( $\mathrm{pH} 7.0$ ), $0.1 \% \beta$-mercaptoethanol, and then vacuum infiltrated with a solution containing $50 \mathrm{mM}$ phosphate buffer ( $\mathrm{pH} 7.0), 0.1 \%$ Triton X-100 and $1 \mathrm{mM}$ 5-bromo-4-chloro-3-indoyl glucuronide (X-Gluc). Tissues were incubated in this solution at $37^{\circ} \mathrm{C}$ overnight, after which time they were fixed in a solution containing 5\% formaldehyde, $5 \%$ acetic acid, and $20 \%$ ethanol, and finally stored in $100 \%$ ethanol. Tissue samples were photographed under a Zeiss dissecting microscope.

\section{ACKNOWLEDGMENTS}

We thank Terri King, Jamus Stonor, and Stefania Crespi for excellent technical assistance. This work was supported in part by Gene Shears Pty Ltd.

\section{LITERATURE CITED}

Aryan, A. P., An, G., and Okita, T. W. 1991. Structural and functional analysis of promoter from gliadin, an endosperm-specific storage protein gene of Triticum aestivum L. Mol. Gen. Genet. 225:65-71.

Bendahmane, M., and Gronenborn, B. 1997. Engineering resistance against tomato yellow leaf curl virus (TYLCV) using antisense RNA. Plant Mol. Biol. 33:351-357.

Brough, C. L., Sunter, G., Gardiner, W. E., and Bisaro, D. M. 1992. Kinetics of tomato golden mosaic virus DNA replication and coat protein promoter activity in Nicotiana tabacum protoplasts. Virology. 187:1-9.

Dry, I. B., Krake, L. R., Rigden, J. E., and Rezaian, M. A. 1997. A novel subviral agent associated with a geminivirus - the first report of a DNA satellite. Proc. Natl. Acad. Sci. USA 94:7088-7093.

Dry, I. B., Rigden, J. E., Krake, L. R., Mullineaux, P. M., and Rezaian, M. A. 1993. Nucleotide sequence and genome organization of tomato leaf curl geminivirus. J. Gen. Virol. 74:147-151.

Groning, B. R., Hayes, R. J., and Buck, K. W. 1994. Simultaneous regulation of tomato golden mosaic virus coat protein and AL1 gene expression: Expression of the AL4 gene may contribute to suppression of the AL1 gene. J. Gen. Virol. 75:721-726.

Haley, A., Zhan, X., Richardson, K., Head, K., and Morris, B. 1992. Regulation of the activities of African cassava mosaic virus promoters by the AC1, AC2, and AC3 gene products. Virology 188:905-909.

Hanley-Bowdoin, L., Elmer, J. S., and Rogers, S. G. 1990. Expression of functional replication protein from tomato golden mosaic virus in transgenic tobacco plants. Proc. Natl. Acad. Sci. USA 87:1446-1450.

Hanley-Bowdoin, L., Settlage, S. B., Orozco, B. M., Nagar, S., and Robertson, D. 1999. Geminiviruses: Models for plant DNA replication, transcription, and cell cycle regulation. Crit. Rev. Plant Sci. 18:71106.

Hofer, J. M. I., Dekker, E. L., Reynolds, H. V., Woolston, C. J., Cox, B. S., and Mullineaux, P. M. 1992. Coordinate regulation of replication and virion sense gene expression in wheat dwarf virus. Plant Cell 4: 213-223.

Hormuzdi, S. G., and Bisaro, D. M. 1995. Genetic analysis of beet curly top virus - examination of the roles of L2 and L3 genes in viral pathogenesis. Virology 206:1044-1054.

Horsch, R. B., Fry, J. E., Hoffmann, N. L., Eichholtz, D., Rogers, S. G., and Fraley, R. T. 1985. A simple and general method for transferring genes into plants. Science 227:1229-1231.

Jefferson, R. A. 1987. Assaying chimeric genes in plants: The GUS gene fusion system. Plant Mol. Biol. Rep. 5:387-405.

Jefferson, R. A., Kavanagh, T. A., and Bevan, M. W. 1987. GUS fusion: Beta-glucuronidase as a sensitive and versatile gene fusion marker in higher plants. EMBO J. 6:3901-3907.

Krake, L. R., Rezaian, M. A., and Dry, I. B. 1998. Expression of the tomato leaf curl geminivirus $C 4$ gene produces viruslike symptoms in transgenic plants. Mol. Plant-Microbe Interact. 11:413-417.

Laufs, J., Wirtz, U., Kammann, M., Matzeit, V., Schaefer, S., Schell, J., Czernilofsky, A. P., Baker, B., and Gronenborn, B. 1990. Wheat dwarf virus Ac/Ds vectors: Expression and excision of transposable elements introduced into various cereals by a viral replicon. Proc. Natl. Acad. Sci. USA 87:7752-7756.

Matzeit, V., Schaefer, S., Kammann, M., Schalk, H. J., Schell, J., and Gronenborn, B. 1991. Wheat dwarf virus vectors replicate and express foreign genes in cells of monocotyledonous plants. Plant Cell 3:247258.

Mullineaux, P. M., Rigden, J. E., Dry, I. B., Krake, L. R., and Rezaian, M. A. 1993. Mapping of the polycistronic RNAs of tomato leaf curl geminivirus. Virology 193:414-423.

Rigden, J. E., Dry, I. B., Mullineaux, P. M., and Rezaian, M. A. 1993. Mutagenesis of the virion-sense open reading frames of tomato leaf curl geminivirus. Virology 193:1001-1005.

Rigden, J. E., Krake, L. R., Rezaian, M. A., and Dry, I. B. 1994. ORF $\mathrm{C} 4$ of tomato leaf curl geminivirus is a determinant of symptom se- 
verity. Virology 204:847-850.

Rigden, J. E., Dry, I. B., Krake, L. R., and Rezaian, M. A. 1996. Plant virus DNA replication processes in Agrobacterium: Insight into the origins of geminiviruses? Proc. Natl. Acad. Sci. USA 93:1028010284.

Stanley, J., Latham, J. R., Pinner, M. S., Bedford, I., and Markham, P. G. 1992. Mutational analysis of the monopartite geminivirus beet curly top virus. Virology 191:396-405.

Sunter, G., and Bisaro, D. M. 1991. Transactivation in a geminivirus: AL2 gene product is needed for coat protein expression. Virology 180:416-419.

Sunter, G., and Bisaro, D. M. 1992. Transactivation of geminivirus AR1 and BR1 gene expression by the viral AL2 gene product occurs at the level of transcription. Plant Cell 4:1321-1331.

Sunter, G., and Bisaro, D. M. 1997. Regulation of a geminivirus coat protein promoter by AL2 protein (trap) - evidence for activation and derepression mechanisms. Virology 232:269-280.

Sunter, G., Hartitz, M. D., and Bisaro, D. M. 1993. Tomato golden mosaic virus leftward gene expression: Autoregulation of geminivirus replication protein. Virology 195:275-280

Timmermans, M. C. P., Das, O. P., and Messing, J. 1994. Geminiviruses and their uses as extrachromosomal replicons. Annu. Rev. Plant Physiol. Plant Mol. Biol. 45:79-112.

Van Engelen, F. A., Molthoff, J. W., Conner, A. J., Nap, J. P., Pereira, A., and Stiekema, W. J. 1995. pBINPLUS: An improved plant transformation vector based on pBIN19. Transg. Res. 4:288-290.

Wartig, L., Kheyrpour, A., Noris, E., Dekouchkovsky, F., Jouanneau, F., Gronenborn, B., and Jupin, I. 1997. Genetic analysis of the monopartite tomato yellow leaf curl geminivirus - roles of V1, V2, and C2 ORFs in viral pathogenesis. Virology 228:132-140.

Zhan, X., Richardson, K. A., Haley, A., and Morris, B. A. M. 1993. The activity of the coat protein promoter of chloris striate mosaic virus is enhanced by its own and C1-C2 products. Virology 193: 498-502.

Zhan, X. C., Haley, A., Richardson, K., and Morris, B. 1991. Analysis of the potential promoter sequences of African cassava mosaic virus by transient expression of the beta-glucuronidase gene. J. Gen. Virol. 72: 2849-2852. 